
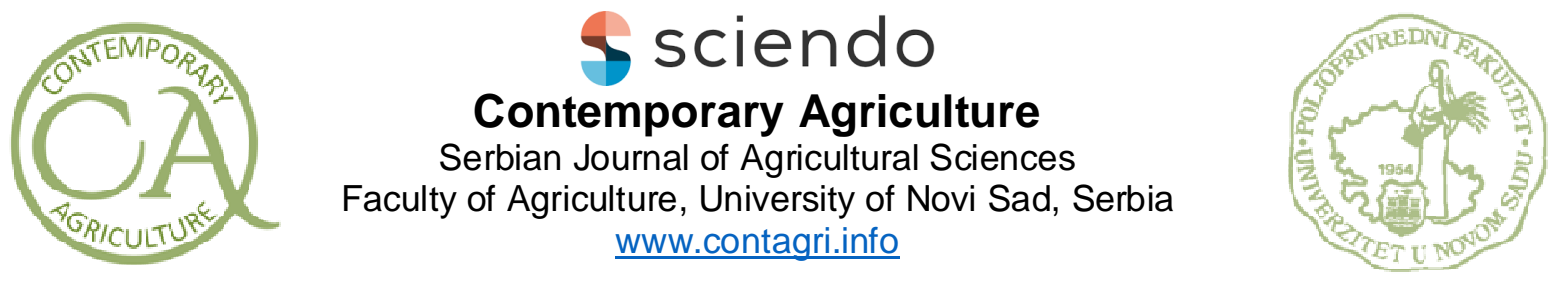

Original scientific paper

UDC: 599.731.1:57.018.026

DOI: 10.2478/CONTAGRI-2021-0002

\title{
PIGLET BODY WEIGHT VARIATION AND THE INFLUENCE OF BIRTH WEIGHT ON PIGLET GROWTH DURING LACTATION AND WEANING
}

\author{
MILE MIRKOV*, IVAN RADOVIĆ, MIROSLAVA POLOVINSKI-HORVATOVIĆ, \\ LJILJANA TOVILOVIĆ, SLOBODAN KONJEVIĆ, VELIBOR VASILJEVIĆ \\ Faculty of Agriculture, University of Novi Sad, Trg Dositeja Obradovića 8, 21000 Novi Sad, Serbia \\ *Corresponding author: mile.mirkov@stocarstvo.edu.rs
}

\begin{abstract}
SUMMARY
Piglets are an important category in pig farming which should, alongside sows, be considered essential production heads. Over the past decades, the intensive selection in pig production has given priority to economically important traits resulting in greater feed utilization and obtaining more piglets from fewer sows. However, such selection practices have failed to improve the overall vitality of piglets and their ability to survive immediately after birth or during their stay in the farrowing unit. Body weight is of great importance in pig production, especially the piglet body weight at birth. A number of parameters can be predicted according to the piglet birth weight: mortality and growth rate, the physiological status of the heard, sensitivity to external influences, vitality and etc. The purpose of this paper is to determine the piglet body weight variation from birth to weaning (measured at birth, 3 hours after birth, 24 hours after birth and at weaning) and to examine the relationship between the birth weight of piglets and their body weight during the transition into nursing. A total of 105 piglets were enrolled in this study from the F1 generation sows followed through eight consecutive parities. The paper presents the results obtained using descriptive statistics, as well as variance and correlation analysis. The relationship between the piglet body weight at different stages of their life and overall production parameters was found to emphasize the centrality of housing conditions as the piglet weight at birth exerts a great impact on the body weight of older piglets, especially in the first days of the piglet life. Therefore, the proper care of piglets in farrowing units is of paramount importance to pig production, especially because piglets have lower body weight at birth nowadays than before.
\end{abstract}

Key words: body weight, growth, piglets

\section{INTRODUCTION}

Low birth weight decreases the survival rate of piglets. The mortality in newborn piglets can vary from farm to farm, ranging from $5 \%$ to as much as $35 \%$, thus posing a major economic issue. A large number of these piglets die in the first $36 \mathrm{~h}$ to $48 \mathrm{~h}$ after farrowing (Eggen, 2019).

The body weight of piglets at birth is an important production parameter as low-birth-weight piglets were found to have a slower growth rate, a longer period of time required to reach market weight, and lighter carcasses on the slaughter line (Powell \& Aberle, 1980; Smith et al., 2007; Rehfeldt et al., 2008).

With the increase in the number of light piglets on the farm, Paredes et al. (2012) state that it is important to identify the population of piglets with lower birth weight in order to adapt the technology to keep such piglets and obtain a more homogeneous piglet group. Hermesch et al. (2001) point out that piglet birth weight is a medium hereditary trait $\left(\mathrm{h}^{2}=0.31\right)$ and should be taken into account when writing breeding programs.

A newborn pig is born with an immature immune system and needs to suckle the first milk (colostrum) within 24 hours after birth. At the beginning of pollination, colostrum contains the most antibodies. That number decreases 
rapidly over time and the colostrum antibody count is reduced by half only after six hours, so it is very important that piglets get colostrum as soon as possible after birth.

The purpose of this paper is to determine the piglet body weight variation from birth to weaning (measured at birth, 3 hours after birth, 24 hours after birth and at weaning) and to examine the relationship between the birth weight of piglets and their body weight during the transition into nursing.

\section{MATERIAL AND METHODS}

The research was conducted on a pig farm in Vojvodina with a capacity of 1,650 sows, featuring a complete production cycle from farrowing to fattening and implementing a purebred selection programme in order to produce F1 gilts. A total of 105 piglets were enrolled in this study from the F1 generation sows (Great Yorkshire $\mathrm{x}$ Landrace) followed through eight consecutive parities. The piglet body weight variation was measured from birth to weaning (namely at birth, 3 hours after birth, 24 hours after birth and at weaning). Statistical data processing was performed using the software package Statistical 13. Both the analysis of variance and correlation were performed using the average value of the piglet body weight measured in order to establish a relationship between body weights at different stages of growth after birth. We also aimed to examine whether the piglet body weight variation at birth affected the piglet body weight variation in the later period of the piglet life.

\section{RESULTS AND DISCUSSIONS}

The description of the variables examined are shown in Table 1, where the measure of central tendency (the arithmetic mean) and measure of data variability (variance, standard deviation and coefficient of variation) are shown, as well as the minimum and maximum values of birth weight, body weight $3 \mathrm{~h}$ after birth, $24 \mathrm{~h}$ after birth and at the transition into nursing.

Table 1. Descriptive statistics and the analysis of variance for the piglet body weight $3 \mathrm{~h}$ after farrowing, $24 \mathrm{~h}$ after farrowing and at the transition into nursing

\begin{tabular}{cccccccccc}
\hline Body weight (BW) & Piglets & Average & Sum & Min & Max & Variance & Std. Dev. & CV & p- value \\
\hline Birth & 105 & 1.28 & 134.18 & 0.47 & 2.00 & 0.08 & 0.29 & 22.34 & - \\
3h after birth & 105 & 1.42 & 149.24 & 0.73 & 1.98 & 0.08 & 0.29 & 20.47 & $0.000000^{* *}$ \\
24h after birth & 105 & 1.54 & 161.31 & 0.80 & 2.10 & 0.08 & 0.28 & 18.50 & $0.000000^{* *}$ \\
Nursing & 105 & 6.79 & 712.79 & 3.55 & 9.95 & 1.92 & 1.39 & 20.41 & 0.070499 \\
\hline
\end{tabular}

Legend: Std.Dev. - standard deviation; CV - coefficient of variation; $p$ - value - the analysis of variance results for the effect of piglet birth body weight on the piglet body weight variation $3 \mathrm{~h}$ after birth, $24 \mathrm{~h}$ after farrowing and at the transition into nursing.

** high statistical significance $\mathrm{p}<0.01$; * statistical significance $\mathrm{p}<0.05$; weak correlation $\mathrm{p}>0.05$

The piglet body weight measured at birth ranged from $0.47 \mathrm{~kg}$ to $2.00 \mathrm{~kg}$. The piglets were measured again $3 \mathrm{~h}$ after birth and the lightest piglet had a body weight of $0.73 \mathrm{~kg}$ and the heaviest piglet was $1.98 \mathrm{~kg}$, which shows that the lighter piglets were making more progress compared to the body weight at birth. Measured 24 hours after birth, the lightest pig had a body weight of $0.80 \mathrm{~kg}$ and the heaviest pig had a body weight of $2.10 \mathrm{~kg}$. At the transition into nursing, the lightest pig had a body weight of $3.55 \mathrm{~kg}$, whereas the heaviest pig was $9.95 \mathrm{~kg}$. The following average body weights of the piglets examined were recorded: $1.28 \mathrm{~kg}$ at birth, $1.42 \mathrm{~kg} 3$ hours after birth, $1.54 \mathrm{~kg} 24$ hours after birth and $6.79 \mathrm{~kg}$ at the transition into nursing. The piglets were weaned at 26 days of age, marking their transition into nursing.

The standard deviations for the piglet body weight at birth, $3 \mathrm{~h}$ after farrowing, 24 hours after birth and at the transition into nursing were $1.28 \pm 0.29,1.42 \pm 0.29,1.54 \pm 0.28$ and $6.79 \pm 1.39$, respectively. The coefficient of variation ranged from $22.43 \%$ at birth to $18.50 \% 24$ hours after farrowing, whereas the coefficients of variation 3 hours after birth and at the translation into nursing were $20.47 \%$ and $20.41 \%$, respectively. The slightly higher coefficient of variation at birth may be accounted for by many factors affecting the body weight at birth, which can subsequently reduce the variability of piglet body weight in the farrowing unit with proper management. 
Farmers have been increasingly focusing on nutrition and the right choice of genetics to increase the birth weight of piglets. Selection is expected to yield better results relative to the vitality of piglets and the acquisition of passive immunity (Quesnel et al., 2012). These shifts should be reflected in both the piglet birth weight and body weight in other production phases. Paredes et al. (2012) reported that the body weight of piglets at birth was 1.40 $\pm 0.37 \mathrm{~kg}$, whereas the body weight at weaning was $7.73 \pm 1.79$. The same authors also state that the piglets whose birth weight is not less than two standard deviations from the average population have the potential to compensate for body weight in the following phases. Škorput et al. (2018) reported the birth weight of $1.32 \pm$ $0.33 \mathrm{~kg}$, which is the closest to the results obtained herein. Fix et al. (2010) recorded a piglet birth weight of 1.43 $\pm 0.35 \mathrm{~kg}$, whereas the piglet body weight at the transition into nursing was $4.92 \pm 1.17 \mathrm{~kg}$.

Devillers et al. (2007) and Quesnel (2011) found that the intake of colostrum in the first 24 hours after birth was 250-300 g, which is crucial for increasing the body weight of piglets in the first 24 hours after birth. Le Dividich et al. (2005) argue that colostrum intake is a highly variable property (varying from 0-700g) and that the ability to absorb colostrum is extremely high when the amount of colostrum is not limited (thus the growth of piglets is positively correlated with the intake of colostrum). Devillers et al. (2004) and Quesnel (2011) state that when colostrum intake is below 140-150g, the energy obtained is insufficient to increase body weight. Quesnel et al. (2012) report that it is necessary to ingest $200 \mathrm{~g}$ of colostrum per piglet in the first 24 hours after birth in order to reduce their mortality by providing passive immunity and ensuring the growth of piglets. The same authors argue that the average body weight of piglets at birth is $1.4 \mathrm{~kg}$.

An analysis of variance was performed to examine the differences in the body weight of the piglets considered (Tab. 1). As seen in Table 1, the body weight of piglets at birth affects $(\mathrm{p}<0.01)$ their body weight recorded $3 \mathrm{~h}$ after birth and $24 \mathrm{~h}$ after birth, whereas no statistical correlation was observed $(\mathrm{p}>0.05)$ between the piglet birth weight and their body weight at the transition into nursing. Wientjes et al. (2013) argue that low birth weight is associated with the reduced survival and a slower growth rate of piglets.

Low-birth-weight piglets were found to have a smaller increase in the body weight during the production phases, which all results in lighter herds in the final stages. Fix et al. (2010) also state that piglets with reduced body weight also have smaller back muscles.

Piglets that have a lower birth weight also have a lower body weight at the age of 42 days. The authors also state that heavier piglets have a higher value precisely because of the higher body weight at weaning (Alison et al., 2007). Škorput et al. (2018) point out that the birth weight significantly affects the daily growth of piglets during lactation and breeding. Piglets with a lower body weight also have a lower daily gain compared to piglets with a higher body weight. The characteristics of large litters are the increased variability of the birth weight of piglets, with a larger share of piglets with a lower birth weight. The authors also state that reduced birth weight is a challenge in production and that it is necessary to reduce the number of avital piglets in order to enable a better survival and satisfactory growth of piglets from the litter of highly prolific sows.

A correlation analysis is used to determine the mutual interaction of the variables considered and to examine the degree and strength of mutual agreement of such variables. The values of the correlation analysis performed for the piglet body weight is shown in Table 2.

Table 2. Piglet body weights measured at birth, $3 \mathrm{~h}$ after birth, $24 \mathrm{~h}$ after birth and at the transition into nursing

\begin{tabular}{|c|c|c|c|c|}
\hline Variables & BW birth & BW $3^{\mathrm{h}}$ after birth & BW $24^{\mathrm{h}}$ after birth & $\mathrm{BW}$ into nursing phase \\
\hline BW birth & 1.000000 & 0.806848 & 0.800391 & 0.444907 \\
\hline $\mathrm{BW} 3^{\mathrm{h}}$ after birth & 0.806848 & 1.000000 & 0.980658 & 0.627012 \\
\hline BW $24^{\mathrm{h}}$ after birth & 0.800391 & 0.980658 & 1.000000 & 0.617860 \\
\hline BW into nursing phase & 0.444907 & 0.627012 & 0.617860 & 1.000000 \\
\hline
\end{tabular}

Legend: BW - body weight

The values obtained are positive, which indicates that an increase in the body weight of one age group is paralleled with an increase in the body weight of another age group. The strongest correlation was found between the body weight of piglets 3 hours after birth and 24 hours after birth. The weakest correlation was observed between the piglet body weight at birth and the piglet body weight at the transition into nursery.

Measurements of the piglet body weight 3 hours after farrowing was aimed at determining the amount of colostrum suckled by the piglets, which could provide a better insight into the movement of their growth. The results obtained indicate that the body weight 3 hours after farrowing has a greater relationship with the body 
weight at the transition into nursing than the birth weight, which is very important for the management of pig breeding. Moreover, it was found that only the piglets that suckle the appropriate amount of colostrum can make progress in the farrowing unit, which is very important for the further stages of production.

Roehe et al. (2009) state that body weight is an important parameter for piglet survival and also recommend measuring the weight of stillborn piglets in order to complete the information on piglet survival. Decaluwe et al. (2014) point out that the intensity of increase in body weight of piglets and the survival rate until the transition into nursery is positively correlated with the birth weight and the intake of colostrum per $\mathrm{kg}$ of body weight.

\section{CONCLUSION}

Litter size is a very important production trait in pig production. Farmers should be well acquainted with the factors that affect the size of the litter because they directly affect the economy and profitability of pig production. An increase in the size of the litter leads to a decrease in the birth weight of piglets. The body weight of piglets is a trait that will be under greater selection pressure in the coming period due to a great need for its increase.

The need for an increase in the piglet birth weight arises from the connection between the birth weight of piglets and their body weight in the following stages of growth. In addition to requiring more attention, lighter piglets have higher mortality rates and lower growth rates, which affect the cost-effectiveness of keeping light piglets. The analysis performed indicates that there is a statistically significant effect of the birth weight of piglets on their body weights measured $3 \mathrm{~h}$ and $24 \mathrm{~h}$ after farrowing, whereas the statistical correlation between the birth weight and the body weight at the transition into nursery was found non-significant. The correlation analysis performed indicates that the greatest positive correlation between the piglet body weights considered was between the body weights measured $3 \mathrm{~h}$ and $24 \mathrm{~h}$ after birth. This relationship indicates an increased intake of colostrum for a given period, which significantly affected the piglet body weight.

Acknowledgements: This research was financed by the Ministry of Education and Science of the Republic of Serbia, Project TR 31081.

\section{REFERENCE}

Alison L.S., Kenneth J.S., Timo V.S., Tom J.B., John W.M. (2007): Effect of piglet birth weight on weights at weaning and 42 days post weaning. Journal of Swine Health and Production, 15(4): 213-218.

Decaluwe R., Maes D., Wuyts B., Cools A., Piepers S., Janssens G.P.J. (2014): Piglets colostrum intake associates with daily weight gain and survival until weaning. Livestock science, 162: 185-192.

Devillers N., Farmer C., Le Dividich J., Prunier A. (2007): Variability of colostrum yield and colostrum intake in swine. Animal, 1: 1033-1041.

Devillers N., Van Milgen J., Prunier, A., Le Dividich J. (2004): Estimation of colostrum intake in the neonatal pig. Animal Science, 78(2): 305-313.

Eggen A. (2019): Raising young piglets. International Pig Topics, 34(5): page 11.

Fix J.S., Cassady J.P., Herring W.O., Holl J.W., Culbertson M.S., See M.T. (2010): Effect of piglet birth weight on body weight, growth, backfat, and longissimus muscle area of commercial market swine. Livestock Science, 127: 51-59.

Hermesch S., Luxford B.G., Graser H.U. (2001): Genetic parameters for piglet mortality, within litter variation of birth weight, litter size and litter birth weight. $14^{\text {th }}$ conference of the Association for the Advancement of Animal Breeding and Genetics, Queenstown, New Zealand, 14: 211-214.

Le Dividich J., Thomas F., Renoult H., Oswald I. (2005): Acquisition de l'immunité passive chez le porcelet: rôle de la quantité d'immunoglobulines ingérées et de la perméabilité intestinale. Journées Recherche Porcine, 37: 443-448.

Paredes S.P., Jansman A.J.M., Verstegen M.W.A., Awati A., Buist W., Hartog den L.A., Heesvan H.M.J., Quiniou N., Henderiks W.H., Gerrits W.J.J. (2012): Analysis of factors to predict piglet body weight at the end of the nursery phase. Journal of Animal Science, 90: 3243-3251.

Powell S.E. \& Aberle E.D. (1980): Effects of birth weight on growth and carcasscomposition of swine. Journal of Animal Science, 52: 748-756.

Quesnel H. (2011): Colostrum production by sows: variability of colostrum yield and immunoglobulin $\mathrm{G}$ concentrations. Animal, 5: 1546-1553.

Quesnel H., Farmer C., Devillers N. (2012): Colostrum intake: Influence on piglet performance and factor of variation. Livestock Science, 146, 105-114. 
Rehfeldt C., Tuchscherer A., Hartung M., Kuhn G. (2008): A second look at the influence of birth weight on carcass and meat quality traits. Meat Science, 78(3): 170-175.

Roehe R., Shrestha N.P., Mekkawy W., Baxter E.M., Knap P.W., Smurthwaite K.M., Jarvis S., Lawrence A.B., Edwards S.A. (2009): Genetic analyses of piglet survival and individual birth weight on first generation data of a selection experiment for piglet survival under outdoor conditions. Livestock Science, 121(2-3): 173-181.

Škorput D., Menčik S., Karolyi D., Luković Z. (2018): Effect of litter size on piglets birth weight. $55^{\text {rd }}$ Croatian and $13^{\text {th }}$ International Symposium od Agriculture. February 18-23, 2018, Vodice, Croatia.

Smith A.L., Stalder K.J., Serenius T.V., Baas T.J., Mabry J.W. (2007): Effect of piglet birth weight on weights at weaning and 42 days post weaning. Journal of Swine Health and Production, 15(4): 213-218.

StatSoft (2019): Statistical - version 13.

Wientjes J.G.M., Soede N.M., Knol E.F., Van der Brand H., Kemp B. (2013): Piglet birth weight and litter uniformity: Effects of weaning-to-pregnancy interval and body condition changes in sows of different parities and crossbred lines. Journal of Animal Science, 91(5): 2099-2107.

Submitted: 7.12.2020.

Accepted: 11.1.2021. 